2012

\title{
The effect of historical legacy on adaptation: do closely related species respond to the environment in the same way?
}

Rachel Prunier

Kent E. Holsinger

University of Connecticut - Storrs, kent.holsinger@uconn.edu

Jane E. Carlson

Follow this and additional works at: https://opencommons.uconn.edu/eeb_articles

Part of the Botany Commons, and the Evolution Commons

\section{Recommended Citation}

Prunier, Rachel; Holsinger, Kent E.; and Carlson, Jane E., "The effect of historical legacy on adaptation: do closely related species respond to the environment in the same way?" (2012). EEB Articles. 32.

https://opencommons.uconn.edu/eeb_articles/32 
1 The effect of historical legacy on adaptation: do closely related species respond to the environment in the same way?

$6 \quad{ }^{1}$ Kellogg Biological Station, Michigan State University, 3700 E. Gull Lake Dr., Hickory

7 Corners, MI 49060, USA.

$8 \quad{ }^{2}$ Department of Ecology and Evolutionary Biology, University of Connecticut, U-3043,

9 Storrs, CT 06268, USA.

10 Running title - The effect of history on adaptation

$11{ }^{3}$ author for correspondence

12 email: prunier@msu.edu

13 telephone: (269) 6712350

14 fax: (269) 671-2165 


\section{Abstract}

16 The many documented examples of parallel and convergent evolution in similar

17 environments are strong evidence for the role of natural selection in the evolution of trait

18 variation. However, species may respond to selection in different ways; idiosyncrasies of

19 their evolutionary history may affect how different species respond to the same selective

20 pressure. To determine whether evolutionary history affects trait-environment

21 associations in a recently diverged lineage, we investigated within-species trait-

22 environment associations in the white proteas, a closely related monophyletic group. We

23 first used MANOVAs to determine the relative importance of shared response to

24 selection, evolutionary history, and unique responses to selection on trait variation. We

25 found that on average, similar associations to the environment across species explained

26 trait variation, but that the species had different mean trait values. We also detected

27 species-specific associations of traits to the environmental gradients. To identify the traits

28 associated uniquely to the environment we used a structural equation model. Our analysis

29 showed that the species differed in how their traits were associated with each of the

30 environmental variables. Further, in the cases of two root traits (root mass and root

31 length:mass ratio), two species differed in the direction of their associations (e.g.

32 populations in one species had heavier roots in warmer areas, and populations in the other

33 species had lighter roots in warmer areas). Our study shows that even in a closely related

34 group of species, evolutionary history may have an effect on both the size and direction

35 of adaptations to the environment.

36 Keywords: Protea, evolutionary history, adaptation, structural equation model 
38 The many examples of convergence and parallel evolution in similar

39 environments are some of the most striking examples of evolution by natural selection,

40 suggesting that species respond similarly to the same environmental selection pressures.

41 The repeated evolution of succulence in plants from arid environments, for example,

42 reflects the consequences of natural selection for water storage in arid environments

43 (Beard 1976, Ogburn \& Edwards 2010). Similarly, the repeated evolution of benthic and

44 limnetic forms of fish (sticklebacks, lake whitefish, pumpkinseed, and bluegill sunfish) in

45 post-glacial lakes is the result of character displacement in response to competition in the

46 newly created lake habitats (reviewed by Schluter \& McPhail 1993).

47 We recognize less often that species may respond to the same selection pressure

48 in different ways. For example, within Drosophila melanogaster, Cohan and Hoffman

49 (1986) found similar responses to selection for ethanol tolerance in replicate experimental

50 populations, but the genetic underpinnings of the ethanol tolerance differed from one

51 replicate to another. The fitness associated with different genotypes at the alcohol

52 dehydrogenase locus depended on the pre-existing genetic background of the individuals.

53 Similarly, Young et al. (2007) showed that shrews with similar diets have functionally

54 similar, but morphologically divergent, jaw structures. Thus, different morphologies may

55 also be the result of similar selection (Young et al. 2007). Even in cases where

56 convergent evolution is well documented, the unique evolutionary history of individual

57 lineages may play a role in how each lineage adapts to its environment. For example, in

58 the radiation of Anolis lizards on Carribean islands, crown giant anoles on the island of

59 Puerto Rico tend to have narrower pectoral width, deeper heads, and wider pelvic widths 
60 than crown giant anoles on other islands (Langerhans et al. 2006). There are even

61 examples where apparently adaptive responses to the same environmental selection arise

62 from trait responses in opposite directions. For example, Nakazato et al. (2008) found

63 that in two species of Andean tomatoes, the between-population associations of plant

64 height with elevation and of days to wilting with mean annual precipitation were similar

65 between species. In contrast, the association of leaf area with elevation depended on the

66 species examined. In Solanum pimpinellifolium, plants tended to have larger leaves in the

67 higher elevation population, and in Solanum lycopersicum var. cerasiforme plants tended

68 to have smaller leaves in the higher elevation population. Differential responses to

69 apparently similar selection pressures could reflect lineage-specific differences in genetic

70 variances and covariances between traits (Arnold et al. 2008, Hanson \& Houle 2008), the

71 vagaries of genetic drift and independent mutational histories (Travisiano et al. 1995), or

72 subtle differences in the environment that were not measured. Different adaptive

73 responses, although affected by non-adaptive forces, are ultimately driven by natural

74 selection to a landscape that has multiple optima.

75 Large-scale trait-environment associations are often attributed to the effects of

76 natural selection. For example, plants from drier and more nutrient poor areas tend to

77 have thicker or denser leaves (Niinemets 2001, Cunningham et al. 1999, Fonseca et al.

78 2000), plant height is correlated with precipitation (Moles 2009), and rooting depth

79 increases with increasing drought (Canadell et al. 1996) and rainfall seasonality (Schenk

$80 \&$ Jackson 2002). All of these associations have been interpreted as adaptive responses to

81 the environment, and these large-scale patterns suggest that species respond predictably

82 to variation along these environmental gradients. Similarly, trait-environment 
83 associations among populations within species are often interpreted as adaptations to the

84 local environment (Endler 1986), but the extent to which these large scale patterns are

85 reflected within species is less explored.

86 In this study we investigated a small evolutionary radiation to determine whether

87 trait variation among populations within species is associated with similar environmental

88 gradients across species and whether this trait variation reflects large-scale trait-

89 environment associations (Table 1). Specifically, we investigated trait-environment

90 associations within the white proteas (Protea sect. Exsertae), a group of six closely

91 related species endemic to the mountains of South Africa that diverged recently (0.34-1.2

92 million years; Valente et al. 2010). While the species are almost completely allopatric,

93 they have broad environmental tolerances (Latimer et al. 2009), and they do not cleanly

94 partition environmental space (Figure 1; see also Latimer 2006). In fact, as Latimer et al.

95 (2009) showed, the differences between species in their mean environments is not enough

96 to account for the almost complete allopatry in this group, suggesting that adaptive

97 differences among populations --in addition to differences among species-- may

98 contribute significantly to the diversity of the group (Carlson et al. 2011).

99 Our previous work on the white proteas found that among-population differences

100 in leaf traits are adaptively associated with climate, e.g., thick or dense leaves appear to

101 be adaptations to a harsh climate (Carlson et al. 2011). These results are consistent with

102 expectations from large-scale surveys of trait-environment correlations across all

103 flowering plant species (Wright et al. 2004). Differences in traits associated with access

104 to nutrients and water and differences in seed size are also likely important foci of

105 adaptation in most plants, including the white proteas. The environments in which the 
106 white proteas grow vary widely in the timing and amount of rainfall (Schulze 2007), in

107 hydrological conditions, and in soil nutrients (Specht \& Moll 1983; Witkowski \&

108 Mitchell 1987). In proteas, long tap roots are needed to reach the water table (Richards $e t$

109 al. 1995, Watt \& Evans 1999), and access to nutrients is facilitated by the production of

110 proteoid roots; specialized cluster roots on lateral roots. Proteoid roots are especially

111 important for uptake of phosphorous (Lamont 1982, Neumann \& Martinoia 2002), but

112 they also enhance uptake of nitrogen and micronutrients (Jeschke \& Pate 1995).

113 Similarly, large seeds have been found to be adaptive in low nutrient conditions (due to

114 better provisioning; Beadle 1966), both within (Bonfil \& Kafkafi 2000,Vaughton \&

115 Ramsey 2001) and across species (Milberg et al. 1998, Shane et al. 2008).

116 Here we use leaf, shoot, and root traits measured in a common environment to

117 answer the following questions: 1. Does evolutionary history, similar evolutionary

118 responses to the environment, or lineage-specific evolutionary responses to the

119 environment play a larger role in the trait diversification of the white proteas? 2. What

120 traits are associated with lineage-specific evolutionary responses to the environment? 3.

121 Do the species-specific trait-environment associations reflect large scale trait-

122 environment correlations?

\section{Materials and Methods}

Study Species

126 The white proteas are a well-supported, monophyletic clade within the genus Protea

127 (Protea section Exertae, Valente et al. 2010). The current taxonomic treatment

128 recognizes 6 species, $P$. aurea (Burm. f.) Rourke ssp. aurea (shuttlecock sugarbush), $P$. 
129 aurea ssp. potbergensis (Rourke) Rourke (potberg sugarbush), P. lacticolor Salisb.

130 (hottentot sugarbush), P. mundii Klotzsch (forest sugarbush), P. punctata Meisn. (water

131 sugarbush), $P$. subvestita N.E. Br. (waterlily sugarbush), and $P$. venusta Compton

132 (creeping beauty). The clade is endemic to Southern Africa, and all of the species but $P$.

133 subvestita are endemic to the Cape Floristic Region (CFR) of southwestern South Africa.

$134 P$. subvestita is native to the Eastern Cape and Kwa-Zulu Natal provinces, as well as

135 Lesotho (Figure 2). The species of the white proteas radiated quickly after the origin of

136 the group, and phylogenetic distance between populations and species is small (Prunier \&

137 Holsinger 2010).

138 All of the white proteas are sclerophyllous evergreen shrubs. $P$. venusta has a

139 sprawling habit, but the remaining species are all ecologically similar. They grow upright

140 and up to 4 meters tall. They are killed by fire, regenerating from seeds stored in

141 serotinous cones (Rebelo 2001). They have largely allopatric ranges, although some

142 populations of $P$. punctata and $P$. venusta are found in close proximity at the tops of the

143 Swartberg and Kammannassie mountains. All are presumed to be pollinated by

144 sugarbirds and sunbirds (Rebelo et al. 1984, Rebelo 2006, de Swardt 2008, Carlson \&

145 Holsinger 2010). Because their flowering periods overlap and most species share bird

146 pollinators, the white proteas often hybridize when grown together in cultivation and

147 when they co-occur in the wild (Rourke 1980, Prunier \& Holsinger 2010).

Sampling Protocol

149 We collected seeds from wild populations in February - April 2008. We sampled 5-6

150 populations from each species (total populations $=30$ ), spanning most of the geographic

151 range of each species (Figure 2, Supplemental Table 1). We excluded P. aurea ssp. 
152 potbergensis from this study because we were able to sample only two populations of this

153 geographically restricted sub-species. Within each population, we collected 5-8

154 seedheads from 8 plants approximately 10 meters apart along a linear transect through the

155 population. We dried the seedheads in a cold room maintained at low humidity until they

156 opened and the single-seeded fruits could be removed. We then selected fruits containing

157 potentially viable seeds by identifying fruits in which the seed was filled and free of

158 insect damage. We stored the fruits containing potentially viable seeds (henceforth seeds)

159 at room temperature until planting.

160

Greenhouse Experiment

161 We weighed, surface sterilized with $10 \%$ bleach, and planted one seed from eight

162 maternal lines per population into each of six standard 288 plug flats (TLC Plastics or

163 similar) filled with a standard nursery soil mix in a complete random block design in

164 September 2008. We moved the seeds to a growth chamber (Conviron, Winnipeg

165 Canada) programmed for short warm days and cool long nights (10 hours: $20{ }^{\circ} \mathrm{C}, 14$

166 hours: $8^{\circ} \mathrm{C}$ ) to simulate autumn in the southern hemisphere (April-June), when the seeds

167 germinate in the wild (Rebelo 2001) and assessed germination every day until 47 days

168 after planting, at which point germination had slowed to less than one plant every other

169 day. One or two days after germination, we moved 2 seedlings from each maternal line to

170 pots $10 \mathrm{~cm} \times 10 \mathrm{~cm}$ wide at the top and $76.2 \mathrm{~cm}$ tall (Stuewe and Sons Inc., Tangent OR)

171 in a greenhouse in Storrs, CT. The pots contained a soil mix with 5 parts peat : 4 parts

172 sand : 2 parts fine perlite : 1 part charcoal. This soil mix is modified from a standard low

173 nutrient greenhouse mix by the addition of sand to provide better drainage. We randomly

174 assigned seedlings to pots within the greenhouse. Supplemental light $\left(80-150 \mu \mathrm{mols} / \mathrm{m}^{2} \mathrm{~s}\right)$ 
175 was added 30 minutes after sunrise and ended 30 minutes before sunset to ensure an even

176 light environment across the greenhouse while maintaining natural red/far red ratios at

177 dusk and dawn. This experiment was performed in the autumn and early winter in the

178 northern hemisphere (September to December) at a latitude higher than the plants' native

179 ranges $\left(41^{\circ} \mathrm{N}\right.$ vs. $\left.33^{\circ} \mathrm{S}\right)$. As a result, the days were shorter than they would experience in

180 the wild, but by less than an hour per day through the duration of the experiment.

181 We kept the pots moist for the first month after transplanting; after that, we

182 watered pots with tap water when they became dry. Due to uncertainty in optimal

183 growing conditions, some plants (4 per population) received no fertilizer. All other plants

184 received 100ml of no-phosphorous fertilizer (60ppm 20-0-20, J. R. Peters, Inc.,

185 Allentown, PA) once every other week. Plants in the no fertilizer treatment received

$186100 \mathrm{ml}$ of tap water instead.

\section{Harvesting and Excavation}

188 All of the plants were excavated in December 2008, 77-83 days after planting. Before the

189 soil was disturbed, we removed the shoot at the soil surface, measured its height and

190 removed a leaf for area and dry weight measurements. We measured fresh leaf area using

191 a LiCor 3100 leaf area meter (LiCor, Lincoln NE) and dry leaf and shoot (stem and

192 leaves) mass after drying leaves and shoots in an oven for two weeks at $60{ }^{\circ} \mathrm{C}$. We

193 extracted the roots by slicing the pots lengthwise and gently teasing the roots from the

194 soil. Some fine roots were lost in extraction. Once the entire root was extracted from the

195 pot, we washed off the remaining soil, measured the length of the longest root and noted

196 the presence or absence of root rot and proteoid roots. Finally, we measured dry weight

197 of the roots after drying them for two weeks at $60{ }^{\circ} \mathrm{C}$. From these primary measurements 
198 we calculated several derived traits: specific leaf area (SLA, leaf area/ leaf dry mass), leaf

199 length:width ratio (LWR, leaf length/leaf width), root:shoot biomass ratio (Rt:ShtM, root

200 mass/shoot mass), root:shoot length ratio (Rt:ShtL, root length/shoot height), and root

201 length:root mass (RtL:M, length of longest root/root mass). The leaf traits and the

202 root:shoot ratios are widely used functional traits, and root length:mass ratio captures

203 important variation in root allocation strategies. Plants that died or had substantial root rot

204 were excluded from the analysis ( $<8 \%$ of plants), resulting in a total of 384 plants (91 no

205 fertilizer, 293 fertilizer).

\section{Climate and Soil Data}

207 To extract climate variables for populations used in the study, we intersected the

208 locations of the sampled populations with layers from the South African Atlas of

209 Agrohydrology, based on more than thirty years of weather data from more than 1000

210 weather stations (Schulze 2007). We reduced the large number of available climate

211 variables to a manageable number by choosing broad environmental categories that we

212 expected to differ among species based on Latimer et al.'s (2009) work in the white

213 proteas. We then performed separate principal components analyses on variables

214 corresponding to these categories. This resulted in one unmanipulated and two composite

215 variables that encapsulate variation in the categories that have been found to be important

216 in delineating white protea distributions (Latimer et al. 2009): seasonal rainfall

217 concentration (PPTCON), winter temperature (COLDPCA), and intensity of dry season

218 drought (DRYPCA). PPTCON ranges from 0 (even rainfall) to 100 (all of the yearly

219 rainfall falling in one month). PPTCON is positively correlated with total rainfall, which

220 we did not include in our analysis $(r=0.51)$. COLDPCA is a measure of the coldness of 
221 winters and is strongly negatively correlated with elevation $(\mathrm{r}=-0.61)$. This axis was

222 calculated as the first axis of a PCA of the average minimum daily temperature in the

223 coldest month and the number of heat units in the coldest three months (the first axis

224 explained $87 \%$ of variation in these two variables). Large values indicate warmer winters.

225 DRYPCA is the first axis of a PCA of the number of days with less than $2 \mathrm{~mm}$ rainfall in

226 the driest three months and the total rainfall during those months (87\% of variation in

227 these two variables). Large values indicate milder, moister dry seasons. These

228 environmental variables are the same as those used in Carlson et al. (2011).

229 To gauge the degree to which plant traits are associated with the soil fertility of

230 their home environments, we collected bulked soil samples at 15 and $30 \mathrm{~cm}$ depth from 3

231 locations at each seed collection site. Bulk samples were dried for 1 week at $60{ }^{\circ} \mathrm{C}$ and

232 analyzed at BEM Labs (Somerset West, SA) for percent N, total P, total K, pH and cation

233 exchange capacity. We constructed a final PCA, FERTPCA, from these NPK

234 concentrations (variable loadings: percent $\mathrm{N} 0.659$, total P 0.496 , total $\mathrm{K} 0.588$, first axis

235 explains $58.7 \%$ of variation). Values for the environmental variables for each population

236 can be found in Supplemental Table 1.

237 1. Does evolutionary history, similar responses to the environment, or unique responses

238 to the environment play a larger role in the trait diversification of the white proteas?

239 To determine the relative contributions of evolutionary history, shared responses

240 to the environment, and unique responses to the environment to trait diversity, we

241 conducted MANOVAs in R (manova, R Core Development Team 2011). The MANOVA

242 approach allows us to account for correlations among the response variables (all plant

243 traits listed above) while testing their relationships with environmental gradients, the 
244 species effect, and the interaction between species and environment. We standardized the

245 environmental predictors so that each one had a mean of zero and a standard deviation of

246 1. This allows us to investigate the relative importance of evolutionary history (species

247 effect), shared response to the environment (environment effects: FERTPCA,

248 COLDPCA, DRYPCA and PPTCON), and unique response to the environment (all

249 species $\times$ environment interactions). For this analysis, we included only the individuals

250 which received fertilizer in the greenhouse, for a total of 293 individuals.

251 We estimated the relative importance of each factor by calculating the partial

252 Wilks's $\eta^{2}$ for each factor. Wilks's $\eta^{2}$ is a measure of the partial variance explained by a

253 factor and the multivariate approximation of SSeffect/(SSeffect + SSerror); (see

254 Langerhans \& DeWitt 2004 for further discussion of partial $\eta^{2}$ ). To create confidence

255 intervals around the estimates of $\eta^{2}$, we jackknifed the analysis by sequentially dropping

256 one individual from the analysis (Davison \& Hinkley 1997). We estimated the marginal

257 SS for each factor as the SS of the last factor added to the model, rotating the order of

258 factors included so that each appeared in the final term. We used this marginal SS to

259 estimate $\eta^{2}$. Because interaction terms are always estimated after main effects, we

260 removed the interaction terms from the model to estimate the $\eta^{2}$ of each of the main

261 factors. The main factor $\eta^{2} \mathrm{~s}$ reflect the variance in multivariate trait space that is due to

262 the average response of species to the four environmental variables and the variance that

263 is explained by the average trait differences between species.

2. Which traits drive any unique response to the environment?

We are interested in the relationships of many traits to the environment. However,

266 these traits did not evolve independently of one another and developmental responses 
267 within an individual are likely to be correlated across several traits. Separate multiple

268 regressions would allow us to investigate the association between individual traits and

269 environmental covariates (as in Nakazato et al. 2008, Carlson et al. 2011). However, they

270 would not allow us to differentiate between direct associations between a trait and the

271 environment and indirect associations that arise because a particular trait is

272 developmentally or genetically correlated with another trait that has a direct association.

273 We use a structural equation model of trait variation to account for trait-trait associations,

274 allowing us to isolate direct associations of traits with environmental features. Structural

275 equation modeling (Jöreskog 1970; Jöreskog \& Sörbom 1996; Lee 2007) provides a

276 general approach to statistical analysis of unobservable, "latent", variables by specifying

277 their relationship to observable, "manifest", variables. By including these latent variables,

278 our model accounts for trait-trait associations and allows us to estimate only 28

279 relationships (lines in Figure 3) rather than trying to examine all 105 pairwise

280 relationships among 15 traits.

281 We analyze the coordinated response of whole plants in terms of four

282 components: root, shoot, leaf, and root:shoot. We are especially interested in these four

283 components because together they represent the three fundamental components of the

284 plant body (root, shoot, and leaf) and root:shoot allocation has long been recognized as a

285 fundamental axis associated with plant adaptation (Orians \& Solbrig 1977, Chapin 1980,

286 Lloret et al. 1999). These are the four latent variables (LV) identified in the center of

287 Figure 3. Each of the manifest variables is related to one of the latent variables and to

288 environmental covariates through a linear regression. For example, if rootlgi is the root

289 length of the $i$ th individual in the sample, then 
rootlg $_{i}=\alpha_{\text {species }[i]}+\beta_{\text {rootlg.root }}$ root $_{i}+\mathbf{g}_{\text {species }[i]} \mathbf{e n v} \mathbf{p o p}[i]_{\text {bin }[i]}+\varepsilon_{i}$,

291 where $a$ is the species-specific intercept; $\beta_{\text {rootlg.root }}$ is the "loading" of rootlg on the root

292 latent variable, $\mathbf{g}_{\text {species }[i]}$ is the species-specific vector of regression coefficients on the

293 environment associated with individual $i, \mathbf{e n v}_{\text {pop[i] }}$ is the vector of environmental

294 covariates associated with the site of origin for individual $i, \varepsilon_{b i n[i]}$ is the random effect

295 associated with the greenhouse bin in which individual $i$ was grown, and $\varepsilon_{i}$ is the random

296 error associated with individual $i$. Notice that the value of the root latent variable is

297 defined only implicitly through its set of regression relationships with corresponding

298 manifest variables, in the case of root those regressions are the ones involving root mass,

299 root length, proteoid roots, main root dead, and root length:mass ratio. To ensure a

300 unique value for each latent variable, the loading of one manifest variable is set to 1 , in

301 our case root length (root LV), the presence of leaves (shoot LV), SLA (leaf LV), and

302 root:shoot weight (root mass/shoot mass, root:shoot LV). The choice of variable used for

303 standardizing the latent variable relationships is arbitrary, because remaining loadings are

304 estimated relative to the loading of 1 for the variable used for standardization. The

305 loadings represent the extent to which each of the manifest variables is associated with

306 the latent variable. Correlations between manifest variables are accounted for through

307 their association with the latent variables.

$308 \quad$ Our data include a mixture of continuous and binary response variables. We used

309 JAGS 2.1.0 (Plummer 2003) to analyze the structural equation model in a Bayesian

310 framework using a logistic link for binary response variables and diffuse normal priors on

311 all loadings and regression coefficients. As suggested by Gelfand et al. (1995), we use

312 hierarchical centering to improve convergence of the MCMC sampler. We report results 
313 from an analysis using 4 independent chains, each with a burn-in of 50,000 iterations,

314 followed by samples taken at 160 step intervals for the next 200,000 iterations, for a total

315 of 5000 samples from the posterior distribution. Standard convergence diagnostics

316 (Gelman \& Rubin 1992) suggest that convergence was satisfactory. All Rhat values are

317 less than 1.04 , most were less than 1.005 , and the effective size of the sample from the

318 posterior distribution of each parameter ranged between 100-5000. For more than $90 \%$ of

319 the parameters, the effective sample size was greater than 500.

320 The model output includes the full posterior distribution for all parameters, which

321 we summarize with the posterior means and 95\% credible intervals. Estimates for which

322 the $95 \%$ credible interval does not overlap zero are statistically distinguishable from zero.

323 As an additional test of the importance of unique responses to the environment we

324 examined two models, one that imposes the same trait-environment association across all

325 species (the common-trait model) and one that allows each species to exhibit a different

326 trait-environment association (the varying-trait model). The common-trait model allows

327 each species to have a different mean trait value, but forces the regression coefficients

328 describing trait-environment relationships to be the same for all species. This model can

329 be summarized as

$330 \quad$ Trait $Z_{i}=\alpha_{\text {species }[i]}+\beta_{\text {trait:latent }}$ latent $+\mathbf{g} \bullet \mathbf{e n v}_{\text {pop }[i]}+\varepsilon_{\text {bin }[i]}+\varepsilon_{i}$

331 where $\alpha_{\text {species[i] }}$ is a species-specific intercept and $\mathbf{g}$ is vector of regression coefficients

332 shared by all species. The varying-trait model can be summarized as:

333 Trait $Z_{i}=\alpha_{\text {species }[i]}+\beta_{\text {trait:latent }}$ latent $+\mathbf{g}_{\text {species }[i]} \bullet \mathbf{e n v}_{\text {pop }[i]}+\varepsilon_{\text {bin }[i]}+\varepsilon_{i}$

334 where $\mathbf{g}_{\text {species }[i]}$ is a vector of species-specific regression coefficients associated with the

335 species to which individual $i$ belongs. 
337 similar to AIC (Spiegelhalter et al. 2002). AIC cannot be used for model choice in a

338 Bayesian context, because it depends on a maximum-likelihood estimate for the

339 parameters. DIC is the Bayesian equivalent, including a component measuring the fit of

340 the model to the data and a component describing the complexity of the model. A

341 difference in DIC larger than 10 units indicates that one model is strongly preferred over

342 the other. If the preferred model is the one in which the species are allowed to respond

343 differently to the environmental gradients, we have evidence that species have different

344 trait - environment relationships. We investigate those differences further by identifying

345 the relationships for which the credible interval does not overlap zero. This is a

346 conservative approach to detecting differences because the failure to detect an effect may

347 reflect a lack of statistical power rather than the absence of an effect. Furthermore,

348 because estimates for individual species trait-environment relationships emerge from a

349 hierarchical model in which species means are drawn from a common distribution, a

350 correction for multiple comparisons is not necessary (Gelman and Hill 2007). In order to

351 retain as large sample size as possible $(\mathrm{N}=384)$, all of the plants were included in this

352 analysis. The effect of the fertilizer was included in the model and does not effect the

353 results reported.

\section{Results}

355 1. Does evolutionary history, similar responses to the environment, or unique responses

356 to the environment play a larger role in the trait diversification of the white proteas?

357 The MANOVA revealed significant effects for all three classes of factors; shared

358 response to the environment, unique responses to the environment, and evolutionary 
359 history (Table 2). Much of the morphological variance among populations was explained

360 by the model, as shown by the Wilks's $\eta^{2}$ values for the species and direct environmental

361 effects. Based on the estimates of partial variance explained (Wilks's $\eta^{2}$ ) and the

362 measures of significance, historical effects and shared response to the environment were

363 similarly important in predicting trait variation. The factor that explained the most

364 variance was shared response to rainfall seasonality, followed by the effect of history

365 (species effect). The unique responses to selection were significant, but mostly smaller

366 than the shared responses to selection. However, the effect of unique responses to winter

367 temperature $\left(\eta^{2}=0.140\right)$ was nearly as large as those of shared responses to winter

368 temperature $\left(\eta^{2}=0.188\right)$.

369 2. Which traits drive the unique response to the environmental gradients?

370 The trait-environment correlations are underpinned by the structure of the structural

371 equation model, which is detailed in Table 3 and Figure 3 . All of the manifest variables

372 were significantly related to the latent variables. The fertilizer treatment had an effect

373 only on the root latent variable.

$374 \quad$ With a delta DIC of -218.3 , the model that allows trait-environment relationships

375 to differ among species ( $\mathrm{DIC}=12152.0)$ is much more strongly supported than the model

376 in which the species are forced to respond similarly to the environment (DIC=12370.3).

377 The significant species-specific trait-environment correlations show why this is the case

378 (Figure 4, Supplemental Table 2). We detected species-specific trait-environment

379 correlations in all species but $P$. venusta. We identified the most species-specific

380 relationships in P. mundii, with 20 out of the 51 significant trait-environment associations

381 occurring between $P$. mundii populations. Winter temperature (COLDPCA) was the 
382 environmental axis most frequently involved in species-specific trait-environment

383 associations with 21 significant trait-environment associations between traits and

384 COLDPCA. Leaf traits varied the most with winter temperature (COLDPCA) and

385 summer drought (DRYPCA). Root traits varied the most with winter temperature

386 (COLDPCA) and rainfall concentration (PPTCON). Associations with shoot, root:shoot,

387 and seed traits were more evenly distributed across the environmental axes.

388 When all (both significant and non-significant) trait-environment associations are

389 considered, species only responded similarly in four of the 60 of the trait-environment

390 combinations (Supplemental Figure 1). Across all species, seeds were always heavier in

391 populations from wetter areas, leaves always had larger areas in wetter areas, shoots were

392 always taller in populations from areas with less seasonal rainfall, and leaves were wider

393 (lower LWR) in areas with more concentrated rainfall.

394 The dissimilarity between species in how their traits vary with their environment 395 becomes even more apparent when only the significant associations are considered. For 396 example, leaf traits in P. aurea, P. lacticolor, P. punctata, and P. subvestita vary along a 397 gradient in the intensity of summer drought (DRYPCA), but the identity of those traits 398 differs among species. In P. aurea and P. lacticolor leaf shape (LWR) varies across the 399 gradient of summer drought, while in $P$. punctata and $P$. subvestita leaf mass varies. In 400 other cases, the same trait varies across an environmental gradient in more than one 401 species, but the direction of the associations differ among species. For example, $P$.

402 mundii and $P$. punctata individuals from warmer areas tend to have heavier root systems, 403 but $P$. aurea individuals from warmer areas tend to have lighter root systems. 
All of the cases in which species differed significantly in the direction of their

405 relationships between a trait and the environment were root traits (arrows in Figure 4). In

406 addition to the differences in root biomass described above, $P$. mundii tends to have more

407 branched root systems (low root length to mass ratio) in warmer areas, while $P$. aurea

408 tends to have less branched root systems (higher root length to mass ratio) in warm areas.

409 Also, $P$. mundii tends to have more branched roots in areas with more concentrated

410 rainfall, but $P$. aurea has less branched roots in areas with more concentrated rainfall.

411 In addition to the opposite responses to COLDPCA and PPTCON listed above,

412 other root traits were correlated with the environmental gradients. They were associated

413 with rainfall seasonality, but the pattern of association varied markedly among species. $P$.

414 mundii had the most varied root response to rainfall seasonality, with fewer proteoid

415 roots, heavier roots, and more branched roots in areas with more seasonal rainfall. $P$.

416 subvestita individuals from areas with more seasonal rainfall had shorter roots. Root traits

417 also varied in response to intensity of summer drought, but only in P. subvestita, in which

418 individuals from wetter areas tended to have heavier, more branched root systems.

419 Species also differed in the association between root traits and winter temperature. In

420 addition to the conflicting trends in $P$. aurea and $P$. mundii described above, $P$. punctata

421 had heavier root systems in warmer areas. We failed to detect significant associations

422 between any root traits and soil fertility.

423 Seed traits did not vary predictably along the environmental gradients we studied.

424 We expected to find heavier seeds in lower nutrient areas (Bonfil and Kafkafi 2000), but

425 we detected no relationships between seed mass and soil fertility (FERTPCA). While

426 seed mass did vary in association with winter temperature and rainfall, the nature of the 
427 association differed among species. In $P$. aurea, populations from warmer areas had

428 smaller seeds. In P. mundii, populations from areas with less seasonal rainfall had smaller

429 seeds. P. lacticolor and P. mundii populations from areas with warmer winters

430 germinated faster.

431 Similarly, root:shoot ratios rarely varied with the environmental gradients in the

432 direction we expected based on many studies of plant allocation strategies in other

433 systems (Orians and Solbrig 1977, Schenk and Jackson 2002). Root:shoot ratios are

434 expected to be higher when water availability is low (McCarthy \& Enquist 2007), but we

435 detected such a relationship only in $P$. mundii. In areas with less intense droughts, $P$,

436 mundii individuals invested more biomass in shoots than in roots. In $P$. aurea and $P$.

437 lacticolor, root:shoot ratio was associated with winter temperature, but not with summer

438 drought. Individuals in these species from areas with warmer winters tended to invest

439 more in shoots than roots.

440 Shoot traits were quite labile in response to the environmental gradients. $P$.

441 mundii, $P$. lacticolor, and $P$. punctata individuals from warmer areas tended to be bigger

442 (more likely to have leaves, have heavier shoots, or taller shoots). P. mundii and $P$.

443 subvestita individuals from more fertile areas tended to be larger as well. However, $P$.

444 mundii, $P$. aurea, and $P$. punctata individuals from areas with more concentrated rainfall

445 tended to be smaller.

446 Many of the trait-environment relationships that we detected in leaves were as

447 expected. For example, we found wider leaves in wetter areas (Cunningham et al. 1999)

448 in P. aurea and P. lacticolor, and heavier leaves in populations from wetter areas in $P$.

449 mundii, $P$. punctata, $P$. subvestita. The one environmental association that we found with 
450 SLA, widely thought to be an important adaptation to many environmental stresses, was

451 also in the direction that we expected. We found that in $P$. aurea, plants from colder sites

452 tended to have lower SLA, thicker or more dense leaves. P. mundii and P. punctata

453 populations from colder areas also tended to have smaller leaves.

\section{Discussion}

Large scale trait-environment associations and the myriad examples of parallel

456 evolution and convergence show that species often respond similarly to similar selection

457 pressures. However, the vagaries of evolutionary history also play a role in both the mode

458 and amount of adaptation to similar selection pressures. Here we show that in a recent

459 evolutionary radiation, similar responses to environmental gradients and species history

460 were the largest predictors of trait variation, but that unique responses to selection were

461 also important in trait diversification. These varied responses suggest that even in a

462 closely related group, species are responding to similar selection pressures in different

463 ways and that evolutionary history can have an effect on both the size and direction of the 464 response to selection.

465 1. Evolutionary history and similar responses to the environment play the largest roles in 466 trait diversification of the white proteas.

467 The strongest predictor of multivariate trait variation is rainfall seasonality (Table 468 2), but the effect of history and other shared responses to the environment were nearly as 469 large. Unique responses to the environment, while detectable, played a smaller role in

470 trait differentiation. The large shared responses of traits to the environmental gradients

471 show that even though the species differ in their mean trait values (significant species

472 effect), many environmental responses are similar. This suggests that much trait 
473 evolution within species represents parallel evolution to similar environmental gradients.

474 In particular, similar responses to rainfall seasonality (PPTCON) was the largest predictor

475 of multivariate trait variation. However, the significant unique responses to the

476 environment indicate that the species also respond differently to each environmental

477 gradient.

478 2. The traits that drive the unique evolutionary response to the environmental gradients

479 In spite of broad similarity in multivariate trait-environment associations detected

480 by the MANOVA, the six species of the white proteas differ in the degree to which their

481 traits are associated with the environment. Using the structural equation model we

482 detected 20 significant trait-environment associations in $P$. mundii, which might be due to

483 the large environmental differences between the eastern and western ranges of $P$. mundii.

484 In contrast, we did not detect any significant relationships between traits and the

485 environment in P. venusta. $P$. venusta is found only near the tops of mountains and does

486 not cover as much of the environmental gradients as do the other species. It also has

487 smaller population sizes than the other species (Rebelo 2006), so it might not harbor the

488 genetic variability necessary to respond to selection.

489 In most of the cases in which more than one species had a significant trait-

490 environment association, the differences were in the strength of the association, but in a

491 few cases there were differences in the direction of the association. In each of the 36 trait-

492 environment combinations (e.g. COLDPCA and seed mass) in which we found at least

493 one significant species-specific correlation, we found at least one species in which the

494 relationship was different from that of other species (either not significant, or in the

495 opposite direction). While others (Travisiano et al.1995, Ruzzante 2003, Gomes \& 
496 Monteiro (2008), and Eroukhmanoff et al. 2009) have shown that evolutionary history

497 affects the magnitude of a selection response, very few studies show closely related

498 species responding to similar selection pressures in opposite directions.

499 All of the traits for which we detected trait-environment associations of opposite

500 signs were root traits, and in all cases, $P$. aurea varied in the opposite direction of $P$.

501 mundii or $P$. punctata. This result is especially surprising, because $P$. aurea's

502 environmental ranges are quite similar to $P$. mundii (Figure 1) and its geographic

503 distribution lies between two disjunct population segments of $P$. mundii. It appears that $P$.

504 aurea and $P$. mundii populations are adapting to similar habitats in different ways. In two

505 out of the three cases when the two species have opposite trait-environment correlations,

506 trait variation in $P$. mundii reflects the pattern expected from broad-scale comparisons.

507 First, in areas with more concentrated rainfall, which in our dataset is strongly correlated

508 with total rainfall, $P$. mundii populations tend to have more branched root systems (lower

509 root length:mass ratio) in areas where rainfall is highly concentrated (higher total), while

510 P. aurea had more simple root systems. Nicotra et al. (2002) found that shrub species

511 from drier areas of Australia invested more in the main axis of their roots than those from

512 wetter areas, similar to the pattern that we detected in P. mundii. Second, P. mundii and

$513 P$. punctata individuals from warmer areas have heavier root systems (and shoots), but $P$.

514 aurea populations have lighter root systems (and non-significantly, shoots). Many studies

515 have shown that plants at higher elevations tend to be smaller than those at lower

516 elevations (Clausen et al. 1940, Woodward 1986, Oleksyn et al. 1998; Byars et al. 2007)

517 and in our system, winter temperature is strongly associated with elevation. In the third 
518 case, we have no expectation for the association between root length:mass ratio and

519 temperature.

520 3. Trait-environment associations rarely reflect large scale patterns.

$521 \quad$ Some of the trait-environment associations that we detected were in the directions

522 that we expected based on trends documented in many other studies, but some were not,

523 and some expected relationships were not detected at all (Table 1). For example, large

524 seed size has long been considered an adaptation to low nutrient soils because of the

525 additional resources that can be stored in a larger seed (Beadle 1966, Stock et al. 1990,

526 Milberg et al. 1998, Vaughton \& Ramsay 2001). Patterns consistent with this expectation

527 have been found in studies of two other members of the Proteaceae, Banksia

528 cunninghamii (Vaughton \& Ramsey 2001) and Protea compacta (Shane et al. 2008). In

529 these studies, large seed size was shown to be an adaptive response to low nutrient soils.

530 In contrast to these expectations, we did not find any association between seed size and

531 soil fertility. P. mundii individuals from areas with more concentrated (and more) rainfall

532 did have larger seeds, but this might be a plastic response as a result of better maternal

533 environment.

534 In root traits, we expected to find a negative association between soil fertility and

535 the presence of proteoid roots, but we found no such association. Only in P. subvestita

536 did we find the expected relationship between intensity of dry-season drought and root

537 weight and root length:mass ratio. Seedlings from populations that experience stronger

538 droughts tended to have lighter, simpler roots systems (for a given length, they weighed

539 less). We found only one association between root:shoot biomass ratio and the intensity

540 of dry season drought, even though this association is a textbook example of a resource 
541 investment trade-off (Larcher 1995) and has often been detected in other studies (e.g.

542 Blum 1996, Lloret et al. 1999, Li \& Wang 2003). We detected this pattern in P. mundii,

543 which has a large range of drought intensities. Our failure to detect this association in

544 other species might reflect a smaller absolute range of drought intensities. Alternatively,

545 rooting depth and root:shoot ratios might have little to do with drought intensity in our

546 species. In Protea, rooting depth is often related to the depth of the water table (Richards

547 et al. 1995, Watt \& Evans 1999), which depends on local geology. None of our

548 environmental variables captures variation in water table depth.

549 The relationships that we found between above-ground traits and the local

550 environment are consistent with those reported earlier for garden-grown plants by

551 Carlson et al. (2011). However, in most cases we only detected a significant association

552 in one or two species. For example, both studies found that plants from areas with more

553 concentrated precipitation have broader leaves (lower LWR), but in our study, it was only

$554 P$. mundii in which we could detect the association. Carlson et al. (2011) ascribe the

555 broader leaves in areas with more seasonal rainfall to the positive association between

556 PPTCON and total rainfall. We may be detecting a relationship between leaf shape and

557 total rainfall, a pattern seen across the Proteaceae (Thuiller et al. 2004, Yates et al. 2010).

558 Narrow leaves lose heat through convection more efficiently than do wider leaves (Yates

559 et al. 2010) and thus are likely to be favored in drier areas where transpirational cooling

560 is particularly costly. Carlson et al. (2011) found that the SLA of plant leaves grown in

561 two common gardens was associated with differences in COLDPCA and DRYPCA of

562 their source populations. In our study, only $P$. aurea populations varied in SLA along the

563 temperature gradient (COLDPCA) and no species had a significant association between 
564 SLA and drought. Our failure to find strong associations between SLA and the

565 environmental gradients in the greenhouse might be due to G X E interactions. The mild

566 conditions in the greenhouse might have resulted in smaller differences in leaf

567 morphology between populations (values of all traits for all populations are included in

568 Supplemental Table 3). Alternately, the lack of significant associations that we detected

569 in the greenhouse might be due to differences in power between the two analysis. In

570 Carlson et al. (2011) the trait-environment associations were estimated using all of the

571 populations in all of the species, whereas in the study presented here, there were only a

572 maximum of 5 populations per species to be used to detect an association between traits 573 and the environment.

\section{Conclusions}

575 Our study shows that even in a closely related group of species, evolutionary

576 history can play a role in trait diversification. While on average, the species responded

577 similarly to the environment, they also had unique responses. In particular, the structural

578 equation model revealed that in some cases, the root traits of $P$. aurea and $P$. mundii

579 varied in opposite directions in response to the same environmental gradient.

580 Evolutionary history can have an effect on adaptation at large and small evolutionary

581 scales. Here we document how evolutionary history can affect trait-environment

582 associations even between very closely related species. We show that evolutionary

583 outcome of selective pressures cannot always be predicted. Further - the lack of

584 correspondence between large scale trait-environment associations and those that we

585 detect within the white proteas suggests that these gradients are unlikely to be driving

586 much of the trait diversification in this group. 
588 The authors thank A.G. Rebelo, M. McQuillian, and G.F. Midgely for support in South

589 Africa, A. M. Gawel for help collecting seeds, and C. Morse for greenhouse support in

590 CT. We thank C. Berdan and D. Fryxell for help in the CT greenhouse, and C. Adams

591 and many EEB graduate students for harvesting roots. A. M. Latimer and A. M. Wilson

592 extracted the climate data. D. Weese gave helpful editorial comments. We thank Cape

593 Nature, the Chief Directorate of Environmental Affairs of the Eastern Cape Province, the

594 Eastern Cape Parks Board, the Department of Water Affairs and Forestry, Ezemvelo

$595 \mathrm{KZN}$, the many reserve managers, and the private landowners for granting access to our

596 wild study populations. This research was funded by NSF DDIG DEB 0709690 awarded

597 to K. Holsinger and R. Prunier and DEB 0716622 awarded to K. Holsinger. 


\section{Literature Cited}

600 Arnold, S.J., Bürger, R., Hohenlohe, P.A., Ajie, B.C., Jones, A. G. 2008. Understanding

601 the evolution and stability of the G-matrix. Evolution 62(10): 2451-2461.

602 Beadle, N. C. W. 1966. Soil phosphate and its role in molding segments of the Australian

603 flora and vegetation, with special reference to xeromorphy and sclerophylly.

$604 \quad$ Ecology 47: 992-1007.

605 Beard, J. S. 1976. The evolution of Australian desert plants. In: Evolution of desert Biota,

606 (Goodall, D. W., ed.). pp. 51-63. University of Texas Press, Austin.

607 Blum, A. 1995. Crop responses to drought and the interpretation of adaptation. Plant

$608 \quad$ Growth Regulation 20:135-148.

609 Bonfil, D., Kafkafi, U. 2000. Wild wheat adaptation in different soil ecosystems as

610 expressed in the mineral concentration of the seeds. Euphytica 114: 123-134.

611 Byars, S. G., Papst, W. \& Hoffman, A. A. 2007. Local adaptation and cogradient

612 selection in the alpine plant, Poa hiemata, along a narrow altitudinal gradient.

$613 \quad$ Evolution 61: 2925-2941.

614 Canadell, J., Jackson, R. B., Ehleringer, J. R., Mooney, H. A., Sala, O. E. \& Schulze, E.-

615 D. 1996. Rooting depth of vegetation types at the global scale. Oecologia 108:

$616 \quad 583-595$.

617 Carlson, J. E. \& Holsinger, K. E. 2010. Natural selection on inflorescence color

618 polymorphisms in wild Protea populations: the role of pollinators, seed predators, 619 and intertrait correlations. American Journal of Botany 97: 934-944. 
620 Carlson, J. E., Holsinger, K. E. \& Prunier, R. 2011. Plant responses to climate in the Cape

621 Floristic Region of South Africa: Evidence for adaptive differentiation in the

$622 \quad$ Proteaceae. Evolution 65: 108-124.

623 Chapin, F. S. 1980. The mineral nutrition of wild plants. Annual Reviews in Ecology

624 and Systematics. 11: 233-260.

625 Cohan, F. M. \& Hoffmann, A. A. 1986. Genetic divergence under uniform selection. II

626 Different responses to selection for knockdown resistance to ethanol among

627 Drosophila melanogaster populations and their replicate lines. Genetics 114: 145-

$628 \quad 163$.

629 Clausen, J. D., D. Keck, and W. Hiesey. 1940. Experimental studies on the nature of

630 species I. Effects of varied environments on western North American plants.

631 Carnegie Institute of Washington Publication, Washington DC.

632 Cunningham, S., Summerhayes, B. \& Westoby, M. 1999. Evolutionary divergences in

633 leaf structure and chemistry, comparing rainfall and soil nutrient gradients.

$634 \quad$ Ecological Monographs 69: 569-588.

635 Davison, A. C. \& Hinkley, D. V. 1997. Bootstrap methods and their application.

636 Cambridge University Press, Cambridge, UK.

637 de Swardt, D. 2008. Family Promeropidae (Sugarbirds). In: Handbook of birds of the

638 world, Vol. 13 (Hoyo, A. E. J. d. \& Christie, D. A., eds.). pp. Lynx Edicions, 639 Barcelona, Spain.

640 Endler, J. A. 1986. Natural selection in the wild. Princeton University Press, Princeton, $641 \quad$ NJ. 
642 Eroukhmanoff, F., Hargeby, A., Arnberg, N. N., Hellgren, O., Bensch, S. \& Svensson, E.

643 I. 2009. Parallelism and historical contingency during rapid ecotype divergence in 644 an isopod. Journal of Evolutionary Biology 22: 1098-1110.

645 Fonseca, C. R., Overton, J. M., Collins, B. \& Westoby, M. 2000. Shifts in trait646 combinations along rainfall and phosphorus gradients. Journal of Ecology 88: $647 \quad 964-977$.

648 Gelfand, A. E., Sahu, S. K. \& Carlin, B. P. 1995. Efficient parameterizations for normal $649 \quad$ linear mixed models. Biometrika 82: 479-488.

650 Gelman, A. \& Hill, J. 2007. Data analysis using regression and multilevel/hierarchical 651 models. Cambridge University Press; Cambridge.

652 Gelman, A. \& Rubin, D. B. 1992. Inference from iterative simulation using multiple $653 \quad$ sequences. Statistical Science 7: 457-472.

654 Gomes, J. L. \& Moneiro, L. R. 2008. Morphological divergence patterns among 655 populations of Poecilia vivipara (Teleostei Poeciliidae): test of an 656 657 812.

658 Hanson, T.F. \& Houle, D. 2008. Measuring and comparing evolvability and constraint in 659 multivariate characters. Journal of Evolutionary Biology. 21: 1201-1219.

660 Jeschke, W. D. \& Pate, J. S. 1995. Mineral nutrition and transport in xylem and phloem 661 of Banksia prionotes (Proteaceae), a tree with dimorphic root morphology.

662 Journal of Experimental Botany 46: 895-905.

663 Jöreskog, K. G. 1970. A general method for analysis of covariance structures. Biometrika 664 57: 239-251. 
665 Jöreskog, K. G. \& Sörbom, D. 1996. LISREL 8: Structural Equation Modeling with the 666 SIMPLIS command language. Scientific Software International, London.

667 Lamont, B. B. 1982. Mechanisms for enhancing nutrient uptake in plants, with particular 668 reference to Mediterranean South Africa and western Australia. The Botanical $669 \quad$ Review 48: 597-689.

670 Langerhans, R. B. \& DeWitt, T. J. 2004. Shared and unique features of evolutionary 671 diversification. The American Naturalist 164: 335-349.

672 Langerhans, R. B., Knouft, J. H. \& Losos, J. B. 2006. Shared and unique features of 673 diversification in greater antillean Anolis ecomorphs. Evolution 60: 362-369.

674 Larcher, W. 1995. Physiological Plant Ecology. 3rd edn. Springer-Verlag, Berlin.

675 Latimer, A. M., Silander, J. A. \& Cowling, R. M. 2005. Neutral ecological theory reveals 676 isolation and rapid speciation in a biodiversity hot spot. Science 309: 1722-1725.

677 Latimer, A. M., Silander, J. A., Rebelo, A. G. \& Midgely, G. F. 2009. Experimental 678 biogeography: the role of environmental gradients in high geographic diversity in 679 Cape Proteaceae. Oecologia 160: 151-162.

680 Lee, S.-Y. 2007. Structural Equation Modeling: A Bayesian Approach. John Wiley \& $681 \quad$ Sons, West Sussex.

$682 \mathrm{Li}, \mathrm{C}$. , and Wang, K. 2003. Differences in drought responses of three contrasting 683 Eucalyptus microtheca F. Muell. populations. Forest Ecology and Management $684 \quad 179: 377-385$

685 Lloret, F., Casanovas, C. and Penuelas, J. 1999. Seedling survival of Mediterranean 686 shrubland species in relation to root:shoot ratio, seed size and water and nitrogen 687 use. Functional Ecology 13:210-216. 
688 McCarthy, M. C. \& Enquist, B. J. 2007. Consistency between an allometric approach and 689 optimal partition theory in global patterns of plant biomass. Functional Ecology

$690 \quad 21: 713-720$.

691 Milberg, P., Peréz-Fernández, M. A. \& Lamont, B. B. 1998. Seedling growth response to 692 added nutrients depends on seed size in three woody genera. Journal of Ecology 693 86: 624-632.

694 Moles, A. T., Warton, D. I., Warman, L., Swenson, N. G., Laffan, S. W., Zanne, A. E., et 695 al. 2009. Global patterns in plant height. Journal of Ecology 97: 923-932.

696 Nakazato, T., Bogonovich, M. \& Moyle, L. C. 2008. Environmental factors predict

697 adaptive phenotypic differentiation within and between two wild andean $698 \quad$ tomatoes. Evolution 62: 774-792.

699 Neumann, G. \& Martinoia, E. 2002. Cluster roots - an underground adaptation for $700 \quad$ survival in extreme environments. Trends in Plant Science 7: 162-167.

701 Nicotra, A. B., Babicka, N. \& Westoby, M. 2002. Seedling root anatomy and

702

703 morphology: an examination of ecological differentiation with rainfall using phylogenetically independent contrasts. Oecologia 130: 136-145.

704 Niinemets, U. 2001. Global-scale climatic controls of leaf dry mass per area, density, and $705 \quad$ thickness in trees and shrubs. Ecology 82: 453-469.

706 Ogburn, R.M., \& Edwards, E.J. 2010. The ecological water-use strategies of succulent plants. Advances in Botanical Research 55: 179-225.

708 Orians, G. H. \& Solbrig, O.T. 1977. A cost-income model of leaves and roots with 709 special reference to arid and semiarid areas. The American Naturalist. 111(980):

710 677:790. 
711 Oleksyn, J., Reich, P.B., Zytkowiak, R., Karolewski, P., Tjoelker, M.G. 2003. Nutrient

712 conservation increases with latitude of origin in European Pinus sylvestris

713 populations. Oecologia 136: 220-235.

714 Plummer, M. 2003. JAGS: A program for analysis of Bayesian graphical models using

715 Gibbs sampling. http://citeseer.ist.psu.edu/plummer03jags.html. Accessed August

$716 \quad 22,2010$.

717 Prunier, R. \& Holsinger, K. E. 2010. Was it an explosion? Using population genetics to

718 explore the dynamics of a recent radiation within Protea (Proteaceae L.).

$719 \quad$ Molecular Ecology 19: 2010.

720 R Development Core Team. 2011. R: A language and environment for statistical

721 computing. R Foundation for Statistical Computing, Vienna, Austria. ISBN 3-

722 900051-07-0, URL http://www.R-project.org/.

723 Rebelo, A. G., W. R. Siegfried, and A. A. Crowe. 1984. Avian pollinators and the

724 pollination syndromes of selected mountain fynbos. South African Journal of

$725 \quad$ Botany 3:285-296.

726 Rebelo, A. G. 1995, 2001. Sasol Proteas: a field guide to the proteas of southern Africa.

$727 \quad$ Fernwood Press, Vlaeberg, SA.

728 Rebelo, A. G. 2006. Protea atlas project website.

729 http://protea.worldonline.co.za/default.htm. Accessed August 20, 2010.

730 Richards, M. B., Stock, W. D. \& Cowling, A. 1995. Water relations of seedlings and

731 adults of two fynbos Protea species in relation to their distribution patterns.

$732 \quad$ Functional Ecology 9: 575-583.

733 Rourke, J. P. 1980. The Proteas of Southern Africa. Purnell, Cape Town. 
734 Ruzzante, D. E., Walde, S. J., Cussac, V. E., Macchi, P. J., Alonso, M. F. \& Battini, M.

735 2003. Resource polymorphism in a Patagonian fish Percichthys trucha

736 (Percichthyidae): phenotypic evidence for interlake pattern variation. Biological

737 Journal of the Linnean Society 78: 497-515.

738 Schenk, H. J. \& Jackson, R. B. 2002. Rooting depths, lateral root spreads and below-

739 ground/above-ground allometries of plants in water-limited ecosystems. Journal

$740 \quad$ of Ecology 90: 480-494.

741 Schluter, D. \& McPhail, J. D. 1993. Character displacement and replicate adaptive

742 radiation. Trends in Ecology and Evolution. 8(6): 197-200.

743 Schultze, R. E. 2007. South African Atlas of Climatology and Agrohydrology. Vol. WRC

744 Report 1489/1/06. pp. Water Research Commission, Pretoria, RSA.

745 Shane, M. W., Cramer, M. D. \& Lambers, H. 2008. Root of edaphically controlled

746 Proteaceae turnover on the Agulhas Plain, South Africa: phosphate uptake

747 regulation and growth. Plant, Cell and Environment 31: 1825-1833.

748 Specht, R. L., \& E. J. Moll. 1983. Heathlands and sclerophyllous shrublands - an

749 overview. Pp. 41-65 in F. J. Kruger, D. T. Mitchell, and J. U. M. Jarvis, eds. The

750 role of nutrients. Springer-Verlag, Berlin, Germany.

751 Spiegelhalter, D. J., Best, N. G., Carlin, B. P. \& Linde, A. V. d. 2002. Bayesian measures

752 of model complexity and fit (with discussion). Journal of the Royal Statistical

$753 \quad$ Society, Series B 64: 583-616.

754 Stock, W. D., Pate, J. S. \& Delfs, J. 1990. Influence of seed size and quality on seedling

755 development under low nutrient conditions in five Australian and South African

756 members of the Proteaceae. Journal of Ecology 78: 1005-1020. 
Thuiller, W., Lavorel, S., Midgley, G., Lavergne, S. \& Rebelo, T. 2004. Relating plant traits and species distributions along bioclimatic gradients for 88 Leucadendron taxa. Ecology 85: 1688-1699.

Travisano, M., Mongold, J. A., Bennett, A. F. \& Lenski, R. E. 1995. Experimental tests of the roles of adaptation, chance, and history in evolution. Science 267: 87-90.

Valente, L. M., Reeves, G., Schnitzler, J., Mason, I. P., Fay, M. F., Rebelo, A. G., et al. 2010. Diversification of the African genus Protea (Proteaceae) in the Cape biodiversity hotspot and beyond: equal rates in different biomes. Evolution 64: 745-760.

Vaughton, G. \& Ramsey, M. 2001. Relationships between seed mass, seed nutrients, and seedling growth in Banksia cunninghamii (Proteaceae). International Journal of Plant Sciences 162: 599-606.

Watt, M. \& Evans, J. R. 1999. Proteoid roots. Physiology and Development. Plant Physiology 121: 317-323.

Witkowski, E. T. F. \& Mitchell, D. T. 1987. Variations in soil phosphorous in the fynbos biome, South Africa. Journal of Ecology 75: 1159-1171.

Woodward, F. L. 1986. Ecophysiological studies on the shrub Vaccinium myrtillus L. taken from a wide altitudinal range. Oecologia 70: 580-586.

Wright I. J., Reich, P. B., Westoby, M., Ackerly, D. D., Baruch, Z., Bongers, F. et al. 2004. The worldwide leaf economics spectrum. Nature 428:821-827.

Yates, M. J., Verboom, G. A., Rebelo, A. G. \& Cramer, M. D. 2010. Ecophysiological significance of leaf size variation in Proteaceae from the Cape Floristic Region. Functional Ecology 24: 485-492. 
780 Young, R. L., Haselkorn, T. S. \& Badyaev, A. V. 2007. Functional equivalence of 781 morphologies enables morphological and ecological diversity. Evolution 61:

$782 \quad 2480-2492$.


Table 1: Expected trait-environment association, the corresponding trait and environment used to detect the association in this study,

784 and the species and direction in which the pattern was found. + indicates that the trait-environment association was in the expected

785 direction, - indicates that the trait-environment association was in the opposite direction from the expectation.

\begin{tabular}{|c|c|c|c|c|}
\hline \multicolumn{5}{|l|}{ Expected Trait-environment } \\
\hline Correlation & Citation & Trait & Environment & Supported in our study? \\
\hline Biomass decreases as elevation & Clausen et al. & root mass, shoot mass, shoot & & $+P$. mundii, $+P$. punctata,$+P$. \\
\hline increases & 1940 & height, leaves present & COLDPCA & lacticolor, -P. aurea \\
\hline Root:shoot ratio increases with & Schenk \& & & & \\
\hline decreased rainfall & Jackson 2002 & root mass/shoot mass & DRYPCA & $+P$. mundii \\
\hline Leaves become larger and wider & Cunningham et & & & \\
\hline with increased rainfall & al. 1999 & LWR & DRYPCA & $+P$. aurea and $+P$. mundii \\
\hline Plant height increases with & Moles et al. & & & \\
\hline increased rainfall & 2009 & shoot height & DRYPCA & No \\
\hline Roots length increases with & Canadell et al. & & & \\
\hline increased drought & 1996 & root length & DRYPCA & No \\
\hline SLA increases with increased & Wright et al. & SLA & DRYPCA & No \\
\hline
\end{tabular}


rainfall

Seeds are larger in lower nutrient

soils

Proteoid roots increase with

decreased soil fertility

SLA decreases with decreased soil

fertility

Root branching increases with more

concentrated rainfall

Root depth increases with

increasing rainfall seasonality

2004

Beadle 1966

Lamont 1982 proteoid roots

Cunningham $e t$

al. 1999

SLA

Nicotra et al. 2002 root length / root mass

Schenk \&

Jackson 2002

seed mass

root length
FERTPCA

PPTCON

+P. mundii, - P. aurea
FERTPCA

FERTPCA

No

No

No 
786 Table 2: MANOVA table including Wilks's $\eta^{2}$, the partial variance explained by each factor, and $95 \%$ confidence intervals around the

787 Wilks's $\eta^{2}$, estimated by jackknifing.

\begin{tabular}{|c|c|c|c|c|c|c|c|c|}
\hline test for & factor & Wilks's $\lambda$ & Approx. F & df & Wilks's $\eta^{2}$ & $\mathrm{p}$ & $2.5 \% \mathrm{CI}$ & $97.5 \% \mathrm{CI}$ \\
\hline shared & COLDPCA & 0.812 & 4.466 & 14,270 & 0.188 & $<0.0001$ & 0.183 & 0.195 \\
\hline response & DRYPCA & 0.783 & 5.346 & 14,270 & 0.217 & $<0.0001$ & 0.211 & 0.222 \\
\hline \multirow[t]{2}{*}{ to environment } & FERTPCA & 0.749 & 6.454 & 14,270 & 0.251 & $<0.0001$ & 0.245 & 0.257 \\
\hline & PPTCON & 0.591 & 13.362 & 14,270 & 0.409 & $<0.0001$ & 0.403 & 0.416 \\
\hline history & species & 0.132 & 9.746 & $70,1289.545$ & 0.333 & $<0.0001$ & 0.331 & 0.335 \\
\hline unique & COLDPCA $\times$ species & 0.471 & 2.92 & $70,1194.326$ & 0.140 & $<0.0001$ & 0.137 & 0.143 \\
\hline response & DRYPCA $\times$ species & 0.612 & 1.856 & $70,1194.326$ & 0.094 & $<0.0001$ & 0.092 & 0.096 \\
\hline \multirow[t]{2}{*}{ to environment } & FERTPCA $\times$ species & 0.673 & 1.479 & $70,1194.326$ & 0.076 & $<0.01$ & 0.074 & 0.079 \\
\hline & PPTCON $\times$ species & 0.622 & 1.786 & $70,1194.326$ & 0.09 & $<0.001$ & 0.089 & 0.093 \\
\hline
\end{tabular}


788 Table 3: Summary statistics of the relationships estimated in the Structural Equation

789 Model; mean, standard deviation, and 95\% credible intervals.

\begin{tabular}{|c|c|c|c|c|}
\hline & mean $(\beta)$ & sd & $2.50 \%$ & $97.50 \%$ \\
\hline \multicolumn{5}{|l|}{ Trait-Latent Variable relationships } \\
\hline SLA-Leaf & $-0.316^{*}$ & 0.073 & -0.464 & -0.176 \\
\hline Leaf LWR-Leaf & $-0.231 *$ & 0.073 & -0.376 & -0.09 \\
\hline Leaf Mass-Leaf & $1.054^{*}$ & 0.037 & 0.984 & 1.13 \\
\hline Root dead-Root & $-2.962 *$ & 0.433 & -3.874 & -2.183 \\
\hline Root length:mass-Root & $0.191 *$ & 0.044 & 0.106 & 0.276 \\
\hline Root weight-Root & $0.497 *$ & 0.032 & 0.436 & 0.559 \\
\hline Proteoid Roots-Root & $1.402 *$ & 0.394 & 0.67 & 2.188 \\
\hline Root: Shoot Mass-RootShoot & $0.514 *$ & 0.053 & 0.411 & 0.617 \\
\hline Shoot Height-Shoot & $1.245^{*}$ & 0.114 & 1.032 & 1.477 \\
\hline Shoot Weight-Shoot & $1.8^{*}$ & 0.111 & 1.592 & 2.027 \\
\hline \multicolumn{5}{|c|}{ External - Latent Variable relationships } \\
\hline Daystogerm - Leaf & -0.035 & 0.038 & -0.113 & 0.039 \\
\hline Daystogerm - Root & $-0.11 *$ & 0.056 & -0.223 & -0.002 \\
\hline Daystogerm - RootShoot & -0.016 & 0.037 & -0.087 & 0.056 \\
\hline Daystogerm - Shoot & -0.023 & 0.016 & -0.055 & 0.009 \\
\hline Fertilizer - Leaf & 0.093 & 0.077 & -0.061 & 0.241 \\
\hline Fertilizer - Root & $-0.277^{*}$ & 0.11 & -0.496 & -0.056 \\
\hline Fertilizer - RootShoot & -0.046 & 0.088 & -0.216 & 0.131 \\
\hline Fertilizer - Shoot & 0.031 & 0.045 & -0.059 & 0.121 \\
\hline
\end{tabular}




\begin{tabular}{|c|c|c|c|}
\hline Seed weight - Leaf & $0.384 *$ & 0.077 & 0.231 \\
\hline Seed weight - Root & $0.218^{*}$ & 0.106 & 0.013 \\
\hline Seed weight - RootShoot & 0.005 & 0.082 & -0.152 \\
\hline Seed weight - Shoot & $0.227 *$ & 0.035 & 0.161 \\
\hline Seed weight - Daystogerm & -0.188 & 0.108 & -0.404 \\
\hline
\end{tabular}

Relationships between Latent Variables

$\begin{array}{lcccc}\text { Root - Shoot } & 0.557 * & 0.047 & 0.46 & 0.645 \\ \text { Leaf - Root } & 0.602 * & 0.04 & 0.519 & 0.679 \\ \text { Leaf - Shoot } & 0.843^{*} & 0.022 & 0.795 & 0.88 \\ \text { Shoot - RootShoot } & -1.473 * & 0.18 & -1.844 & -1.128 \\ \text { Root - RootShoot } & 1.104 * & 0.046 & 1.018 & 1.198\end{array}$

790 Note: The relationships between traits and latent variables are one way, but the

791 relationships among Root, Shoot, and Leaf latent variables are reciprocal. The

792 relationships between the RootShoot latent variable and Root and Shoot latent variables

793 are also one-way with Root and Shoot informing RootShoot. * indicates relationships for

794 which the $95 \%$ credible intervals do not overlap zero.

795 
796 Figure legends:

797 Figure 1: White protea climate envelopes in three dimensions: COLDPCA (PCA

798 summarizing coldness of winter), DRYPCA (PCA summarizing intensity of summer

799 drought), and PPTCON (rainfall seasonality). Values were obtained by intersecting the

800 locations of all observed populations of each species from the Protea Atlas (a database of

801 250k presence/absence observations of all species in the Proteaceae; Rebelo 2006) with

802 the South African Atlas of Agrohydrology (Schulze 2007).

803

804 Figure 2: Sampling locations and ranges of the white protea species. Inset is a map of 805 Africa, with enlarged area in the box.

807 Figure 3: Relationships between latent variables, measured traits, and outside factors

808 estimated in the SEM analysis. Latent variables are represented by grey ovals and traits

809 and outside factors (seedwt=seed weight, daystogerm=\# of days to germination,

810 fert=fertilizer treatment) are represented by white boxes. All variables are standardized,

811 and the relative size of each relationship is indicated by the width of the arrow that

812 connects the variables. Black arrows indicate positive relationships and grey arrows

813 indicate negative ones. Dotted arrows are non-significant relationships. Asterisks indicate

814 the traits for which the regression coefficients were set to 1.

816 Figure 4: Correlations between measured traits and the local environment. The

817 environment is summarized along four axes COLDPCA (coldness of winter), DRYPCA

818 (intensity of summer drought), and PPTCON (rainfall seasonality). All traits and 
819 environments are standardized and the size of each circle is proportional to the size of the

820 effect. Black circles are positive relationships, grey circles are negative. Only significant

821 relationships are shown. Black arrows indicate reversals in trait-environment correlations.

$822 P$. venusta is excluded from the figure because it had no significant trait-environment

823 correlations. 